\title{
Magnetism Study in Transition Metal Doped Superatoms: $\mathrm{TMLi}_{12}(\mathrm{TM}=\mathrm{Sc}-\mathrm{Fe})$
}

\author{
Lijuan Yan, Jianmei Shao* and Chunlei Chen* \\ College of Electronics \& Information Engineering, Guangdong Ocean University, Zhanjiang 524088, China
}

*Corresponding author: Jianmei Shao and Chunlei Chen, College of Electronics \& Information Engineering, Guangdong Ocean

University, Zhanjiang 524088, China

\section{ARTICLE INFO}

Received: 幽 June 24, 2019

Published: 慧 July 02, 2019

Citation: Lijuan Y, Jianmei S, Chunlei C. Magnetism Study in Transition Metal Doped Superatoms: $\mathrm{TMLi}_{12}(\mathrm{TM}=\mathrm{Sc}-\mathrm{Fe})$. Biomed J Sci \& Tech Res 19(2)-2019. BJSTR. MS.ID.003281.

\begin{abstract}
Through unbiased global optimization and density functional theory method, a series of stable icosahedral magnetic $\mathrm{TMLi}_{12}(\mathrm{TM}=\mathrm{Sc}-\mathrm{Fe})$ clusters are identified, where the $3 \mathrm{~d}$ transition-metal element is embedded at the center of $\mathrm{Li}_{12}$ cage. Energy calculations and the moderate HOMO-LUMO gaps confirm their stability. Molecular orbitals analysis reveals the superatomic properties.
\end{abstract}

Keywords: Superatoms; Stability; Magnetic Moment; Electronic Shell; Binding energy; $\mathrm{Eb}$

\section{Introduction}

In recent years, the field of cluster science have been increasingly investigated [1-3]. Among them, superatoms, which can be used to mimic the chemical behaviour of atoms in the periodic table, are the 'magic' atomic clusters [4]. The valance electron of superatoms are accommodated in a series of quantized orbitals labeled as 1S, 1P, 1D, 2S, 1F, 2P, etc. Their stability can be understood by the jellium model, where the motions of electrons are assumed in a uniform positive spherical background composed by ionic charge of the cluster's atomic nuclei and the innermost electrons [5,6]. The corresponding electronic levels in superatoms are $1 \mathrm{~S}^{2} 1 \mathrm{P}^{6} 1 \mathrm{D}^{10} 2 \mathrm{~S}^{2} 1 \mathrm{~F}^{14} 2 \mathrm{P}^{6}$, etc., where $2,8,18,20,34$ and 40 , etc, are associated with magic clusters. Such superatoms are non-magnetic due to all the electrons paired. Khanna and coworkers proposed the concept of magnetic superatoms and took an isolated $\mathrm{VCs}_{8}$ and a ligated protected $\mathrm{MnAu}_{24}(\mathrm{SH})_{18}$ as examples in 2009, where the magnetic moments were acquired by the orbitals localized at the atomic sites and the stability was imparted by the diffuse states [7]. Since then, many reports about magnetic superatoms are emerged [8-12]. In this work, we use $\mathrm{Li}_{13}$ as a prototype to design a new type superatom, which is formed by replacing the central atom of $\mathrm{Li}_{13}$ with a $3 \mathrm{~d}$ transition-metal element. Then, the stability and electronic properties of $\mathrm{TMLi}_{12}$ are discussed.

\section{Computational Methods}

The structure of $\mathrm{TMLi}_{12}(\mathrm{TM}=\mathrm{Sc}, \mathrm{Ti}, \mathrm{V}, \mathrm{Cr}, \mathrm{Mn}, \mathrm{Fe}, \mathrm{Co}$ and $\mathrm{Ni})$ are located by unbiased global optimization method and density functional theory (DFT) of Gaussian16 package [13]. Frequency calculations prove that the icosahedron is a true energy minimum. The spin multiplicities (SMs) of each isomer are determined by comparison their energy of the same structure with different SMs, where the SM of the lowest energy structure is that of ground states. All the calculations are completed by adopting pure functional PW91 and SDD the basis set $[14,15]$.

\section{Results and Discussion}

The geometric of pure $\mathrm{Li}_{13}$ cluster is a centred icosahedron with $I_{h}$ symmetry as shown in Figure 1 and [16]. With the central lithium atom is substituted by $3 \mathrm{~d}$ transition-metal elements $(\mathrm{Sc}, \mathrm{Ti}$, $\mathrm{V}, \mathrm{Cr}, \mathrm{Mn}, \mathrm{Fe}, \mathrm{Co}$ and $\mathrm{Ni}$ ), and the structure retain still except CoLi and $\mathrm{NiLi}_{12}$ by unbiased global optimization method. To identify the stability of $\mathrm{TMLi}_{12}(\mathrm{TM}=\mathrm{Sc}, \mathrm{Ti}, \mathrm{V}, \mathrm{Cr}, \mathrm{Mn}$, and Fe), we examine

a) The average binding energy $\left(\mathrm{E}_{\mathrm{b}}\right)$ per atom of the transition metal atom to the cluster,

b) The energy gaps of the highest occupied and lowest unoccupied molecular orbitals (HOMO-LUMO gaps). 

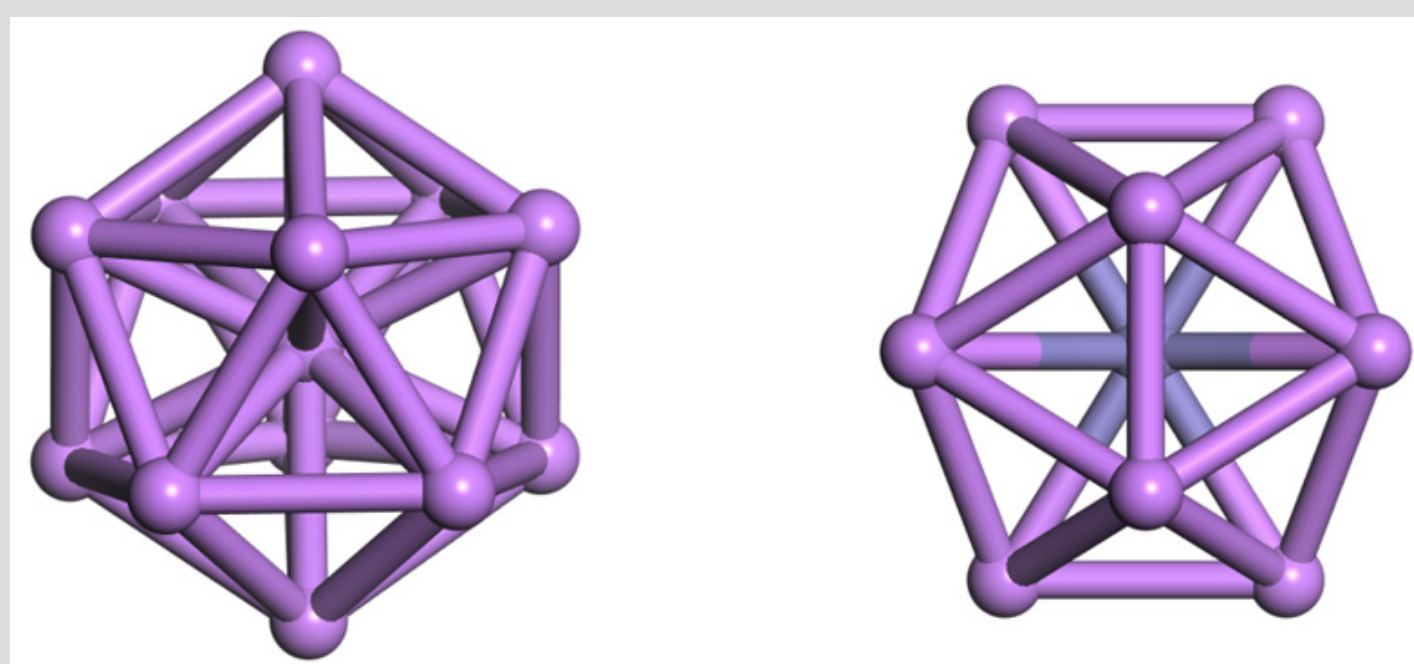

Figure 1: Diagrams of pure $\mathrm{Li}_{13}$ and $\mathrm{TM} @ \mathrm{Li}_{12}(\mathrm{TM}=\mathrm{Sc}, \mathrm{Ti}, \mathrm{V}, \mathrm{Cr}, \mathrm{Mn}$, and $\mathrm{Fe})$ clusters with $\mathrm{I}_{\mathrm{h}}$ symmetry.

The $\mathrm{E}_{\mathrm{b}}$ is defined as the following equation:

$$
E_{b}\left(T M L i_{12}\right)=\frac{E(T M)+12 E(L i)-E\left(T M L i_{12}\right)}{13}
$$

Where TM represents the $3 \mathrm{~d}$ transition-metal atoms $\mathrm{Sc}, \mathrm{Ti}$, $\mathrm{V}, \mathrm{Cr}, \mathrm{Mn}$, and Fe. $\mathrm{E}\left(\mathrm{TMLi}_{12}\right)$ is the total energy of the $\mathrm{I}_{\mathrm{h}}$ symmetry icosahedron. $\mathrm{E}(\mathrm{Li})$ and $\mathrm{E}(\mathrm{TM})$ are the total energy of the Li and TM atoms in the free state, respectively. From (Figure 2), it can be seen that the $\mathrm{E}_{\mathrm{b}}$ of $\mathrm{TMLi}_{12}(\mathrm{TM}=\mathrm{Sc}, \mathrm{Ti}, \mathrm{V}, \mathrm{Cr}, \mathrm{Mn}, \mathrm{Fe}$ ) clusters is higher than that of the corresponding pure $\mathrm{Li}_{13}$. This indicate that embedding $3 \mathrm{~d}$ transition-metal elements ( $\mathrm{Sc}, \mathrm{Ti}, \mathrm{V}, \mathrm{Cr}, \mathrm{Mn}$, and $\mathrm{Fe}$ ) into $\mathrm{Li}_{12}$ cage can enhance its stability. However, the results of energy gaps give small values, where large HOMO-LUMO gaps can enhance their stability and reduce their reactivity. Taking the gaps of typical magnetic superatoms as reference, the gaps are moderate, for example, V@ $\mathrm{Na}_{8}(0.69 \mathrm{eV})$ [7] and $\mathrm{MnSr}_{9}(0.35 \mathrm{eV})$ [8]. In addition, the gaps are underestimated by the standard GGA functionals, and an accurate gap need apply the hybrid functionals, for instance, the gap of $\mathrm{FeLi}_{12}$ is $0.65 \mathrm{eV}$ at the calculations of TPSSH/SDD. To examine the cause of their stability, we analyze the associated molecular orbitals, and take $\mathrm{MnLi}_{12}$ as representative cluster, which has 19 effective valence electrons offered by lithium atom $\left(2 s^{1}\right)$ and manganese atom $\left(4 s^{2} 3 d^{5}\right)$, respectively. As shown in Figure 3, the lowest state over the whole cluster has $1 \mathrm{~S}$ character. The next five states are 1D states while the degeneracy is broken into three groups of 1, 2 and 2 orbitals due to the oblate shape. The same occurs in the next $1 \mathrm{P}$ states, which is split into $\mathrm{P}_{\mathrm{x}^{\prime}} \mathrm{P}_{\mathrm{y}^{\prime}} \mathrm{P}_{\mathrm{z}}$ and the degeneracy is completely removed. The next state is $2 \mathrm{~S}$, and the last occupied state has $2 \mathrm{D}$ character. Therefore, the electronic filling order of $19 \mathrm{e} \mathrm{MnLi}_{12}$ is $1 \mathrm{~S}^{2} 1 \mathrm{D}_{\alpha}{ }^{5} 1 \mathrm{P}^{6} 1 \mathrm{D}_{\beta}{ }^{4} 2 \mathrm{~S}_{\alpha}{ }^{1} 2 \mathrm{D}_{\alpha}{ }^{1}$, where the HOMO-LUMO gap $(0.07 \mathrm{eV})$ is from the energy difference of $2 \mathrm{D}_{\alpha} 1$ and $1 \mathrm{D}_{\beta}{ }^{1}$. With three unpaired electrons, the total spin magnetic moment of $\mathrm{MnLi}_{12}$ is $3.0 \mu \mathrm{B}$. Based on above discussion, the centred icosahedral $\mathrm{MnLi}_{12}$ is a magnatic superatom, where its stability is acquired by having a spin magnetic moment of $3.0 \mu \mathrm{B}$. All the other clusters are magnatic superatoms except $\mathrm{CrLi}_{12}$, which is a non-magnatic superatom due to all the electrons paired. The analysis is similar, and their magnetic moments also are display in Figure 2.
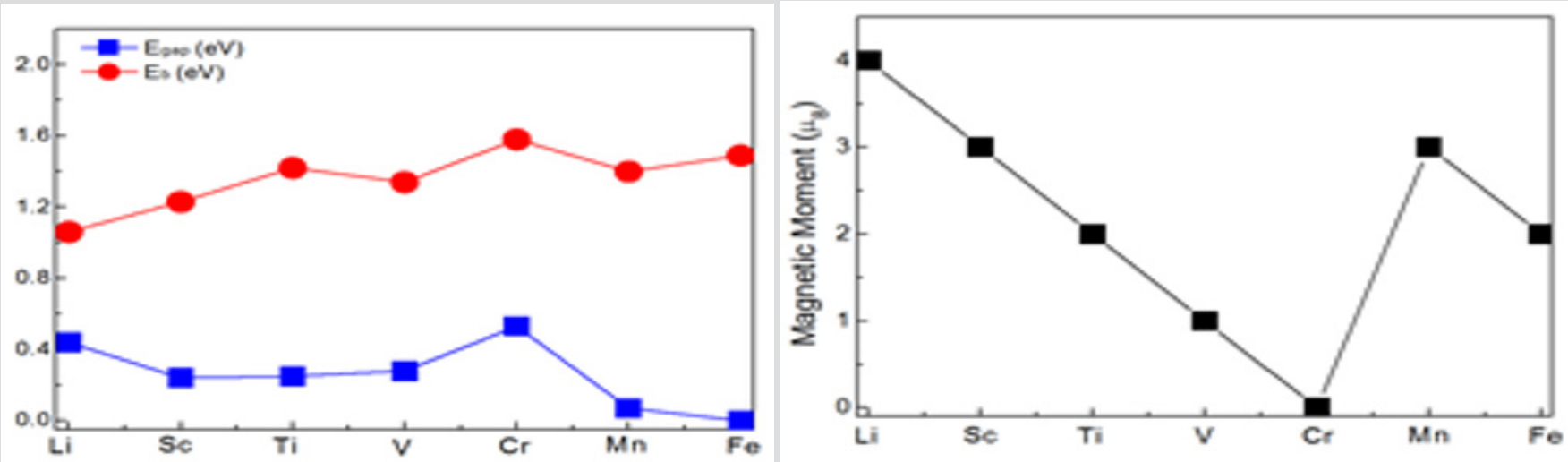

Figure 2: Comparison of $\mathrm{E}_{\mathrm{b}}$ and $\mathrm{E}_{\text {gap }}$ and the total magnetic moment of pure $\mathrm{Li}_{13}$ and $\mathrm{TMLi}_{12}(\mathrm{TM}=\mathrm{Sc}-\mathrm{Fe})$. 


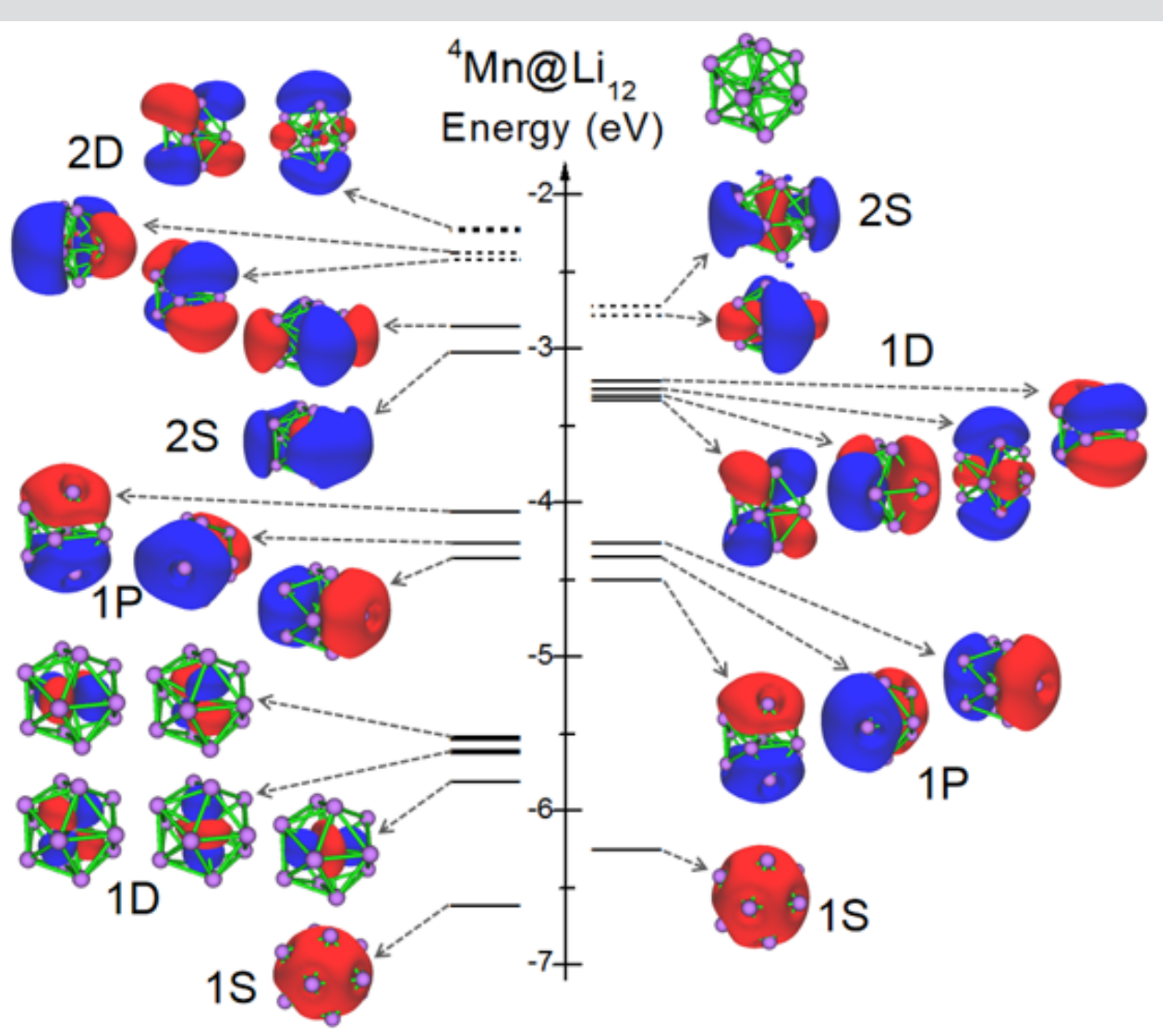

Figure 3: One electron energy levels and MOs of $\mathrm{Mn} @ \mathrm{Li}_{12}$. Continuous lines represent the filled levels while the dotted lines is corresponding to the unfilled states.

\section{Conclusion}

In the work, we have demonstrated that cluster $\mathrm{Li}_{12}$ endohedrally doped with a $3 \mathrm{~d}$ transition-metal element (Sc, Ti, V, $\mathrm{Cr}, \mathrm{Mn}$, and $\mathrm{Fe}$ ) can form stable clusters with $\mathrm{I}_{\mathrm{h}}$ symmetry. These high symmetric clusters are identified as magnetic superatoms except $\mathrm{CrLi}_{12}$, which is non-magnetic. Such a combination could be extended, where the transition-metal element in the same main element is embedded and superatoms also exist due to the same effective valence electrons.

\section{Acknowledgement}

This work is supported by the PhD Starting Fund of Guangdong Ocean University (120702/R17077).

\section{References}

1. Claridge SA, Castleman Jr AW, Khanna SN, Murray CB, Sen A, et al. (2009) Cluster-assembled materials. ACSnano 3(2): 244-255.

2. Castleman JAW, Khanna SN (2009) Clusters, superatoms, and building blocks of new materials. J Phys Chem C 117(7): 2664-2675.

3. Ghosh A, Mohammed OF, Bakr OM (2018) Atomic-level doping of metal clusters. Acc Chem Res 51(12): 3094-3103.

4. Knight WD, Clemenger K, de Heer WA, Saunders WA, Chou MY, et al. (1984) Electronic shell structure and abundances of sodium clusters. Phys Rev Lett 52(24): 2141-2143.

5. Ekardt W (1984) Work function of small metal particles: Self-consistent spherical jellium-background model. Phys Rev B 29(4): 1558-1564.
6. Ekardt W (1986) Theory of electronic excitations in coated metal particles: Jellium-on-jellium model. Phys Rev B 34(2): 526-533.

7. Reveles JU, Clayborne PA, Reber AC, Khanna SN, Pradhan K, Sen P, Pederson MR (2009) Designer magnetic superatoms. Nat Chem 1: 310315.

8. Medel V, Reveles JU, Khanna SN (2012) Magnetism of electrons in atoms and superatoms. J Appl Phys 112(6): 064313.

9. Zhang M, Zhang J, Feng X, Zhang H, Zhao L, et al. (2013) Magnetic superatoms in VLin $(\mathrm{n}=1-13)$ clusters: A first-principles prediction. J Phys Chem A 117(48): 13025-13036.

10. Zhang X, Wang Y, Wang H, Lim A, Gantefoer G, et al. (2013) On the existence of designer magnetic superatoms. J Am Chem Soc 135(12): 4856-4861.

11. Shibuta M, Ohta T, Nakaya M, Tsunoyama H, Eguchi T, et al. (2015) Chemical characterization of an alkali-like superatom consisting of a Taencapsulating $\mathrm{Si}_{16}$ cage. J Am Chem Soc 137(44): 14015-14018.

12. Bergeron DE, Castleman Jr. AW, Morisato T, Khanna SN (2004) Formation of $\mathrm{Al}_{13} \mathrm{I}-$ : Evidence for the superhalogen character of $\mathrm{Al}_{13}$. Science 304(5667): 84-87.

13. Frisch MJ, Trucks GW, Schlegel HB, Scuseria GE, Robb MA, et al. (2016) Gaussian 16, revision b.01; gaussian, inc.: Wallingford, ct.

14. Hay PJ, Wadt WR (1985) Ab initio effective core potentials for molecular calculations. Potentials for the transition metal atoms Sc to $\mathrm{Hg}$. J Chem Phys 82: 270-283.

15. Perdew JP, Wang Y (1992) Accurate and simple analytic representation of the electron-gas correlation energy. Phys Rev B Condens Matter 45: 13244-13249.

16. Fournier R, Bo Yi Cheng J, Wong A (2003) Theoretical study of the structure of lithium clusters. J Chem Phys 119: 9444-9454. 


\section{ISSN: 2574-1241}

DOI: 10.26717/BJSTR.2019.19.003281

Jianmei Shao. Biomed J Sci \& Tech Res

(c) (i) This work is licensed under Creative

Submission Link: https://biomedres.us/submit-manuscript.php

$\begin{array}{ll}\text { BIOMEDICAL } & \text { Assets of Publishing with us } \\ \text { RESEARCHES } & \text { - Global archiving of articles } \\ \text { - Immediate, unrestricted online access } \\ \text { - Rigorous Peer Review Process }\end{array}$

